\title{
Sciendo
}

\section{Freelancing in Croatia: Differences among Regions, Company Sizes, Industries and Markets}

\author{
Ana Globočnik Žunac, Sanja Zlatić, Krešimir Buntak \\ University North, Croatia
}

\begin{abstract}
Background: Freelancers have a significant impact on economic growth due to their specific skills that are nowadays often used as complements to the regular full-time workforce of a company, not as their competition. Objectives: The study aims to investigate employers' attitudes towards the employment of freelancers in Croatia, taking into account the place of establishment, the operational market, the size, and the industry of the organization hiring freelancers. Methods/Approach: Differences among organizations according to their attitudes towards freelancers are analyzed by multiple 2xc Fisher's exact tests with the Monte Carlo Simulation, and binomial logistic regression analysis. Results: Significant differences are found in terms of the operational market and the industry in which the company operates. Besides, the binomial logistic regression analysis identified the following independent constructs as significant predictors of hiring freelancers: the region of the company's seat, company size, and area of operation. Conclusions: The national legislation should complement the developmental policies to encourage employment and especially self-employment of freelancers.
\end{abstract}

Keywords: freelancing; outsourcing; business externalization; hiring; logistic regression JEL classification: J24

Paper type: Research article

Received: 17 Sep 2020

Accepted: 15 Mar 2021

Citation: Globočnik Žunac, A., Zlatić, S., Buntak, K. (2021), "Freelancing in Croatia: Differences among Regions, Company Sizes, Industries and Markets", Business Systems Research, Vol. 12, No. 1, pp. 109-123.

DOI: https://doi.org/10.2478/bsrj-2021-0008 


\section{Introduction}

Modern employment in the context of resource management in business is taking a new form. Outsourcing has been a common form of choice for an efficient and profitable business for a long time, and Marshall et al. (2015) talk about it as the organizational policy that has a direct impact on the organizational structure. The term which is frequently changed in use by synonyms to externalize or subcontract refers to the business practice of hiring a person (or a company) to perform business activities, which were usually done by a company's employees. Kavčić et al. (2015a) think that process of outsourcing fill gaps for the organizations have due to the lack of needed resources. As well, they see this process as the key for a developmental policy as the outsourcing decision is the base for a long-term competitive and successful business. Outsourcing can be used as a measure to reduce costs, but also as a solution when a highly skilled worker or professional is needed when the company does not have them within their workforce (Cieslik, 2015).

Davis-Blake and Uzi (1993) implicate four factors are influencing the use of outsourcing as a form of employment. These are the cost of employment, the external environment, the size of the organization and the degree of bureaucracy, and the skills required to perform work tasks. All mentioned highlights the importance and significance of managing the relationship with this other, external side, of the company where Piltan and Sowlati (2016) talk about issues springing from the need of joint decision making, information sharing, taking joint risks, and developing trust and commitment. These issues are the possible reasons for an organization not being keen on externalizing its activities. Being bigger and used to sharing all mentioned can be one of the possible factors of influence when deciding to externalize activities. In favor of that, Kavčić et al. (2015b) say that companies are complex social, economic, and technical systems and the very complexity is the reason to choose the outsourcing model. They think that each participant in the outsourcing relationship needs two features. First, they need to be specialized in their core competencies but as well, they need to have the creativity and the ability to cooperate.

This form of employment brings up in focus the freelancers. The term freelancer is used for someone who is self-employed and works independently of a company, works alone or with partners in occupations that are non-manual and require specific knowledge and skills, e.g. software development, web design, translating services, creative writing, business consultants, managers, and others (Kitching, 2015; Kozica et al., 2014; Malaga, 2016; Kazia et al., 2014). However, in the very term 'freelancer' there is freedom engraved according to Henning (2011) these have everything but freedom, as they are characterized by the constant pressure of doing the present job activity and thinking about the ahead, projects and in the same time having in focus the constant need of being networked. Freelancers are perceived as high-skilled workers who can respond to the requirements of a company (Burke, 2015). Hoedemaekers (2020) talks about Stanworth and Stanworth's typology of three reasons why someone becomes a freelancer: a person is unable to find inhouse jobs; a person is freelance by choice or due to some circumstances outside of work. The same author states that according to Fraser and Gold (2001) some start freelancing out of necessity but remain there by choice. This reason shows that the root is not only in the characteristics of the person but as well, it might be in environmental circumstances. In any case, the concept of freelancing is related to the concept of independent professional, and it brings new features to the human resource theory. Volberda (1998) sees a challenge for management in the need to create a balance between job interchanges and retention of previously known, 
taking into account the dynamics of operations, the results of intelligence gathering, and the multi-directional causal connections between the employees and the organization. But on the other hand, as being such an important resource, many professionals would find the interest and embark on a venture of freelancing and face a big challenge in the shape of the need to develop their market. To do that they need to have adequate characteristics and knowledge which is not (mostly) connected to their expertise.

Freelancers' market does not exist before it is developed by the very employee. The question of the market for freelancers arose as well as the need to find out whether the employers recognized the opportunity. Therefore, the research presented in this paper had the aim to get insight into the side of employers and find out what impacts their choice to hire freelancers. The following factors of possible influence are taken: region of where is the seat of the company, the size of the organization, the market in which the company operates, and activities it is engaged in. The research was conducted with the help of the Croatian Chamber of Commerce and through their network all; the registered business entities were targeted. Unfortunately, not all targeted responded which influenced the size of the sample. The research instrument was developed and possible differences of the independent variables in terms of hiring freelancers were analyzed, achieved by multiple 2xc Fisher's exact tests with Monte Carlo Simulation.

The paper introduces the topic and the review of relevant literature at the beginning, which is followed by a detailed description of the research methodology and statistical methods used. Results of the research according to the discussion of one block of four hypotheses are presented in the second part of the paper. The conclusion gives research limits and guidelines for further investigation of the topic.

\section{Literature review}

In Croatia, a topic frequently mentioned in the media and expert roundtables is the position of freelancers, i.e. not recognizing this form as one of the possible forms of employment as well as the other legislative frameworks and support for freelancers. Freelancers Union in the USA (since 1995) or the Association of Independent Professionals and the Self-Employed (IPSE) in the UK (since 1999) have been there to provide any help, advice, health insurance, education, or anything else a freelancer or an independent professional might need. In Croatia, the Croatian Independent Professionals Association (CIPA) has been providing Croatian freelancers with the same support since 2013.

The main feature of freelancers is independence. Kozica et al. (2014) simply define freelancers as individuals who do some business as independent contractors while Shepard (2018) thinks that this independence enables independent professionals to work on more than one project at the same time, but they are free to decide on the number of companies they are selling their knowledge and skills to, on the time they will spend on their work, and on the place where they will do their job, which is often in their home or a co-working space. The question is whether there is a market for multitudinous projects in Croatia for any type of freelancers' activity and in any region of Croatia or is this opportunity reserved for only those operating in the big business developed zones or large cities. Not recognizing freelancing by economic policymakers as a possibly good option leads to self-employment in forms such as one-man-band, or starting a company with only one employee. Often these are Home-Based Businesses (HBBs) which Mason et al. (2010) named insignificant businesses which as such is often undervalued. Kitching and Smallbone (2012) think that freelancing as a form of employment is neglected by researchers of small 
business enterprises and they agree that it should be considered differently not as part of SME. Freelancers as a large subset of the small business population are an interesting target group and attention to them should be paid. Mason et. al (2010) consider that this form of work fosters distinctive geography of the area as rural and non-metropolitan parts.

Home becomes a central location for practicing labor and according to the Labor Force Survey, 3.1 million people are working mainly from home in the United Kingdom which is $11 \%$ of the workforce (Ruiz and Walling, 2005). This type of employment prescribes a different approach to business and entails entrepreneurial assumptions, which often complicates the life and business of individuals who could solve their problems as freelancers. New technologies that create networks of young people and professionals, but also a high level of specialization in certain areas, on the other hand, affect the new nature of employment. Some authors see freelancing as a future trend especially with the development of these technologies that enable work done from any distant place. According to Gheorghe (2015), Croatia has a 0.20 -market share of freelancing and is at $23^{\text {rd }}$ position on the list were the first in India with 34.19 market share or the USA which is with 14.15 at the second place. Countries that are closer to Croatia as Macedonia and Bulgaria have a similar share while Serbia has a market share of 1.08. Beck (2000) examines how work has become unstable in the modern world and presents a new vision for the future. He states that there are no longer safe job paths and predicts the end of traditional working practices. According to him, new models include forms of self-organizing, which is necessary to provide equal access to comprehensive social protection. These changes in access to employment will lead to freeing individuals to become authors of their own 'do-it-yourself' biographies as work is 'chopped up by time and by contract.

A complete insight into the situation on the labor market in Croatia from the aspect of self-employment shows factors that influence freelancers' opportunities. As such, it speaks of the possibilities concerning their activities and provides significant prerequisites for business planning of freelancers, but also guidelines for the future definition of economic employment policy and the prerequisites for smooth operation and development of freelance activities. Bolarić Škare (2012) presented self-employment benefits that vary in percentage in different counties in Croatia and according to her data; the highest percentage is in the big urban and industrial towns, which could be the standpoint to the conclusion that the place where the organization is situated can be of influence when subcontracting the activity performed by a freelancer. The market for activities of freelancers in Croatia according to the research presented in this paper is not limited by the size of the company nor by where it is situated in Croatia, which speaks of equal opportunities throughout the country. A significant influence on the freelancers' opportunity has the market in which the company operates and the activity the company is engaged which is following the results of a survey conducted by Kavčič et al. (2015a) in Slovenia. They say that the importance of particular services varies from organization to organization considering the particular segment to which the organizations belong.

Kitching and Smallbone (2012) discuss the term of freelancing and agree with many other researchers (Storey et al., 2005; Holgate and McKay, 2009; Moeran, 2009, according to Kitching and Smallbone, 2012) who use it as for independent workers in creative and media occupations, though some authors mostly see them in the field of software development, IT and engineering, while Leighton and Brown (2013) unite the concept and talk mostly about journalists, designers, IT experts, and different 
consultants. Academic researchers typically use the term freelance to refer to ownaccount workers in creative and media occupations, including journalism television and radio, film, publishing, public relations, translation services, and artists (ibid), and while so Kitching and Smallbone (2012) discuss own-account workers in managerial, professional, scientific and technical occupations that should also be treated as part of the freelance workforce. Solicitors working for personal clients are excluded from this but those serving both organizational and personal end-users might be defined as freelance. At the beginning of investigating freelancers, the researchers focused on a narrow set of occupations and sectors. Expansion of employment externalization brought in other jobs and professions. The reason for this expansion Beardwell et al. (2004) sees in the competitive labor market. Johnson and Ashforth (2008) call it the 'paradox of externalization' as they argue the problem of relying on external employees in the process of connecting with customers and building customer-oriented services while Beardwell et al. (2004) talks about the new feature of employment as 'not providing commitment'. Externalization of employment through outsourcing was the research topic of Harland, et al. (2005) who view it as a term not only used for support services but also activities 'closer to core' ones. Cheesley (1997 according to Harland et al., 2005) that in the UK hospital trusts and health authorities outsourced clinical support services, e.g. provision of sterile supplies and patient appliances, and parts of occupational health, pathology, radiology, and pharmacy services. This is evidence that outsourcing is equally relevant for "core" as well as "non-core" activities.

\section{Methodology}

\section{Research instrument}

Results presented in this paper are part of the much broader survey on freelancers for which a special research instrument in form of a questionnaire was developed (Table 1). The main purpose of this research is to explore the differences in the decision-making of freelancer's employment. Research questions examined in this paper are shown in the table below. Dependent variable measures if the company hires freelances.

\section{Table 1}

Research instrument description

\begin{tabular}{|c|c|}
\hline Item & Modalities \\
\hline $\begin{array}{l}\text { Have you ever hired a freelancer in } \\
\text { your company? }\end{array}$ & Yes, no \\
\hline $\begin{array}{l}\text { Which county is the location of } \\
\text { headquarter of your company? }\end{array}$ & Country codes \\
\hline $\begin{array}{l}\text { In which category does your } \\
\text { company belong (according to the } \\
\text { Accounting Act }(N N 78 / 15,134 / 15)) ?\end{array}$ & Micro, medium, and large \\
\hline $\begin{array}{l}\text { In what market does your company } \\
\text { operate? }\end{array}$ & $\begin{array}{l}\text { Locally, regionally (more than two counties), Croatia, } \\
\text { countries around Croatia, European Union, or worldwide. }\end{array}$ \\
\hline What does your company do? & $\begin{array}{l}\text { Individual and small series production, process industry, } \\
\text { service activities, and logistics, public administration } \\
\text { services, services of utility and public companies, } \\
\text { independent profession (lawyers, dentists, freelance artists), } \\
\text { agriculture and fisheries, education, or other (specify). }\end{array}$ \\
\hline
\end{tabular}




\section{Data}

Data collection is achieved by distributing a questionnaire, conducted online through the survey tool esurveycreator.com. The target population consists of small, medium, and large companies based in Croatia. An e-mail with the link to the webbased questionnaire was sent to the companies in Croatia by the Croatian Chamber of Commerce. During the time interval between the $4^{\text {th }}$ and the $25^{\text {th }}$ of June 2018, the survey was completed by 158 respondents.

\section{Statistical methods}

Research questions are evaluated with the construction of a binary logistic regression model, where the independent variables are the region where the company is seated, the size of the organization, the market on which it operates, and the type of its activity. The dependent, binary outcome variable of the model is, whether the given company has hired a freelancer (yes/no). Outliers are searched iteratively and those cases, in which standardized residuals display greater than 2 standard deviations, are excluded from the model. Model fit is interpreted with chisquare goodness-of-fit statistic and the Hosmer and Lemeshow goodness-of-fit test (Hosmer Jr., Lemeshow, \& Sturdivant, 2013). For the interpretation of the model's explained variance, Nagelkerke's $R^{2}$ will be evaluated (Nagelkerke, 1991), which can reach a theoretical maximum of 1 , contrary to Cox and Snell's $R^{2}$ (Field, 2018).

In the conducted logistic regression model, the paper used indicator dummy coding for the categorical predictors with the first category as the reference. In this manner, the City of Zagreb served as the reference category of region, "micro" held the place of reference by company size, while local firm became the reference category of market operation and individual and small series production were present as the reference category of operational type.

The statistical significance of the model's independent variables is interpreted with their Wald test results $\left(z^{2}\right)$ to determine, whether their addition significantly improves the model's predictive ability (Field, 2018). Since the B coefficients of the predictors only show the log odds of occurrence for a one-unit change in the respective independent variable, if all other independent ones are kept constant, the paper also notes the exponential $B$ coefficients $\left(e^{B}\right)$ with their $95 \%$ confidence intervals for the change of odds (Field, 2018).

\section{Validity}

The discriminative ability of the model is presented with a classification table including the model's sensitivity (i.e., the percentage of cases where the positive outcome was classified correctly) and its specificity (i.e., the percentage of cases where the negative outcome, in this case not hiring a freelancer, was classified correctly)(Steyerberg, 2009). Additionally, the model's positive and negative predictive values are calculated and discussed.

The accuracy of the constructed binary logistic regression model is interpreted with the Receiver Operating Characteristics (ROC) curve to assess the model's ability to correctly classify cases (i.e., its discriminating ability) in the determination of hiring a freelancer (Steyerberg, 2009). The model's sensitivity and specificity are discussed and interpreted, followed by the summary of the constructed ROC curve with the area under the curve (AUC), which is equivalent to its concordance probability (Gönen, 2007). The AUC, which represents the ability of the model to discriminate between the two outcome possibilities of hiring a freelancer, ranges from 0.5 and 1.0 and is interpreted according to the general guideline of Hosmer and colleagues (Hosmer Jr. et al., 2013, p. 177). 


\section{Results}

From the 158 respondents of the study, $44.3 \%$ were male $(n=70)$ and $48.7 \%$ female $(M=77)$, while further 11 respondents did not indicate their gender. Only 1 respondent $(0.6 \%$ of the sample) stated age between 18 and 25 years, further $20.3 \%$ of the respondents $(n=32)$ marked the group of 26-35 years of age. The age groups 36-45 and $46-55$ were both marked by $29.1 \%$ of the sample, 46 respondents each. The age group of 55 years or older was stated by $20.9 \%$ of the sample $(n=33$ participants).

The highest number of companies were sampled in the City of Zagreb $(n=51)$, while the least participants were from the region of Central Croatia $(n=15)$. The percentage proportion of hiring freelancers compared to all respondents in the respective region was the highest in the City of Zagreb ( $n=36,70.6 \%$ of the sampled companies hired one already), while the lowest proportional percentage was found in Northern Adriatic and Lika region ( $n=10,41.7 \%$ ). The following table (Table 2) represents the regional comparisons of hiring freelancers in Croatia.

\section{Table 2}

Number of companies in different Croatian regions according to freelancers' hiring

\begin{tabular}{|c|c|c|c|c|}
\hline \multirow[b]{2}{*}{ Region } & \multicolumn{2}{|c|}{$\begin{array}{l}\text { Companies that hire } \\
\text { freelancers }\end{array}$} & \multicolumn{2}{|c|}{$\begin{array}{l}\text { Companies that do not hire } \\
\text { freelancers }\end{array}$} \\
\hline & $\mathbf{n}$ & $\%$ & $\mathbf{n}$ & $\%$ \\
\hline Central and Southern Adriatic & 11 & $64.7 \%$ & 6 & $35.3 \%$ \\
\hline Northern Adriatic and Lika & 10 & $41.7 \%$ & 14 & $58.3 \%$ \\
\hline Eastern Croatia & 12 & $63.2 \%$ & 7 & $36.8 \%$ \\
\hline Northwestern Croatia & 14 & $46.7 \%$ & 16 & $53.3 \%$ \\
\hline Central Croatia & 9 & $60 \%$ & 6 & $40 \%$ \\
\hline City of Zagreb & 36 & $70.6 \%$ & 15 & $29.4 \%$ \\
\hline Total & 92 & $59 \%$ & 64 & $41 \%$ \\
\hline Fisher test & \multicolumn{4}{|c|}{$p=0.145$} \\
\hline
\end{tabular}

Source: Author's work

Table 3 depicts the number of freelancers hired in companies of different sizes. The majority of the sampled respondents were employees in micro firms $(n=111,71.6 \%$ of the sample), while the least amount of respondents worked in medium $(n=11,7.1 \%)$ and large companies $(n=11,7.1 \%)$. The proportional percentage of hired freelancers was the highest in medium firms $(n=7,63.6 \%)$, while the lowest percentage was found in the case of little companies ( $n=10,45.5 \%)$.

Table 3

Number of companies in the different company according to freelancers' hiring

\begin{tabular}{lcccc}
\hline & $\begin{array}{c}\text { Companies that hire } \\
\text { freelancers }\end{array}$ & \multicolumn{2}{c}{$\begin{array}{c}\text { Companies that do not hire } \\
\text { freelancers }\end{array}$} \\
Company size & $\mathrm{n}$ & $\%$ & $\mathrm{n}$ & $\%$ \\
Micro & 68 & $61.3 \%$ & 43 & $38.7 \%$ \\
Little & 10 & $45.5 \%$ & 12 & $54.5 \%$ \\
Medium & 7 & $63.6 \%$ & 4 & $36.4 \%$ \\
Large & 6 & $54.5 \%$ & 5 & $45.5 \%$ \\
Total & 91 & $58.7 \%$ & 64 & $41.3 \%$ \\
Fisher test & \multicolumn{4}{c}{$\mathrm{p}=0.535$} \\
\hline
\end{tabular}

Source: Author's work 
The number of freelancers hired is analyzed according to different operational areas as well (Table 4). The majority of the respondents stemmed from firms that operate within Croatia ( $n=41,26.3 \%)$, while the least percentage of respondents are employed in companies that operate worldwide. The highest proportional percentage of hired freelancers was found in worldwide companies $(n=15,93.8 \%$ of respondents from worldwide companies hired a freelancer already), while the least percentage of firms who hired freelancers was found in companies that operate locally $(n=6,24 \%)$.

\section{Table 4}

Number of companies in different operational markets areas according to freelancers' hiring

\begin{tabular}{|c|c|c|c|c|}
\hline \multirow[b]{2}{*}{ Operational markets } & \multicolumn{2}{|c|}{$\begin{array}{l}\text { Companies that hire } \\
\text { freelancers }\end{array}$} & \multicolumn{2}{|c|}{$\begin{array}{l}\text { Companies that do not hire } \\
\text { freelancers }\end{array}$} \\
\hline & $\mathbf{n}$ & $\%$ & $\mathbf{n}$ & $\%$ \\
\hline Locally & 6 & $24 \%$ & 19 & $76 \%$ \\
\hline $\begin{array}{l}\text { Regionally (more than two } \\
\text { countries) }\end{array}$ & 8 & $40 \%$ & 12 & $60 \%$ \\
\hline Croatia & 25 & $61 \%$ & 16 & $39 \%$ \\
\hline Countries around Croatia & 13 & $72.2 \%$ & 5 & $27.8 \%$ \\
\hline European Union & 25 & $69.4 \%$ & 11 & $30.6 \%$ \\
\hline Worldwide & 15 & $93.8 \%$ & 1 & $6.3 \%$ \\
\hline Total & 92 & $59 \%$ & 64 & $41 \%$ \\
\hline Fisher test & & & .001 & \\
\hline
\end{tabular}

Source: Author's work

There are significant differences in the employment of freelancers in different operational types according to the presentation in Table 5. The majority of respondents were employed in companies engaged in the business area of service activities and logistics ( $n=89,58.9 \%)$, whilst the least amount of participants stemmed from public companies and those that specialized themselves for services of utilities $(n=2,1.3 \%)$. The proportional percentage of hired freelancers was found in the case of independent professions such as lawyers, dentists, and free artists ( $n=8,88.9 \%)$, while no freelancers were employed in the sampled companies of services of utility and public companies as well as agriculture and fisheries.

Table 5

Number of companies in different types of activity according to freelancers' hiring

\begin{tabular}{|c|c|c|c|c|}
\hline \multirow[b]{2}{*}{ Type of activity } & \multicolumn{2}{|c|}{$\begin{array}{l}\text { Companies that hire } \\
\text { freelancers }\end{array}$} & \multicolumn{2}{|c|}{$\begin{array}{l}\text { Companies that do not hire } \\
\text { freelancers }\end{array}$} \\
\hline & $\mathbf{n}$ & $\%$ & $\mathbf{n}$ & $\%$ \\
\hline $\begin{array}{l}\text { Individual and small series } \\
\text { production }\end{array}$ & 23 & $71.9 \%$ & 9 & $28.1 \%$ \\
\hline Process industry & 6 & $66.7 \%$ & 3 & $33.3 \%$ \\
\hline Service activities and logistics & 46 & $51.7 \%$ & 43 & $48.3 \%$ \\
\hline $\begin{array}{l}\text { Services of utility and public } \\
\text { companies }\end{array}$ & 0 & $0 \%$ & 2 & $100 \%$ \\
\hline $\begin{array}{l}\text { Independent profession } \\
\text { (lawyers, dentists, free artists) }\end{array}$ & 8 & $88.9 \%$ & 1 & $11.1 \%$ \\
\hline Agriculture and fisheries & 0 & $0 \%$ & 3 & $100 \%$ \\
\hline Education & 5 & $71.4 \%$ & 2 & $28.6 \%$ \\
\hline Total & 88 & $58.3 \%$ & 63 & $41.7 \%$ \\
\hline Fisher test & & $p<0.001$ & & \\
\hline
\end{tabular}

Source: Author's work 
$2 \times$ c Fisher's exact tests with Monte Carlo simulation (2000 replicates) were used to determine whether the proportions between the groups of the independent variables (region of the company's seat, size, area of operation, and operation type) are significantly different in terms of hiring a freelancer. Since Fisher's exact tests are omnibus, pairwise group comparisons will be made during post hoc tests with Benjamini-Hochberg adjustment.

In the case of the different regions where the seat of the company is, there were no significant proportional differences in terms of hiring a freelancer $(p=0.145)$. The analysis of different company sizes (micro, little, medium, large) and the difference in terms of their hiring a freelancer was not proportionally significant either ( $p=0.535$ ). However, significant differences in the categories of company operation area were observable in terms of hiring a freelancer $(p<0.001)$. The post hoc test revealed that there were significant proportional differences in terms of hiring a freelancer between locally based firms and Croatia-wide companies ( $p=0.015)$, those that reside in the countries around Croatia $(p=0.009)$, the European Union $(p=0.005)$ and the whole world $(p<0.001)$. Furthermore, regional firms differed also significantly from worldwide companies.

Significant differences were also observable in the proportions of types of activity in terms of hiring freelancers $(p<0.001)$. The post hoc test revealed that there were two significantly different pairs in this variable: companies with the profile of agriculture, fisheries, and public sector differed significantly from firms in the industrial and small series production ( $p=0.035)$ and companies in independent professions, such as lawyers, dentists and free artists ( $p=0.035)$.

After the analysis or Fisher's exact tests, the binary logistic regression was conducted. Casewise outliers of the model were detected iteratively in three stages. In the first stage, 5 cases were excluded, followed by additional 4 cases in the second stage and 2 cases in the third stage.

During the baseline analysis, the model without independent variables, only including the constant was evaluated. Without the inclusion of the independent variables, the model assumes that all firms hired freelancers, thereby correctly classifying $58.8 \%$ of the cases.

The logistic regression model was statistically significant, determined by omnibus Chi-square statistics, $\chi^{2}(19)=120.002, p<0.001$. Furthermore, the Hosmer and Lemeshow goodness of fit test was used to determine the adequacy of the model in terms of how well it performs in predicting the categorical outcome of hiring a freelancer. The Hosmer and Lemeshow test was not statistically significant with a result of $\chi^{2}(8)=4.292, p=0.830$, indicating a good fitting model. Explained variation was evaluated through Nagelkerke R2, whereby the model explained $77.5 \%$ of the variance.

Table 6

Classification table of the effectiveness of the predicted classification against the practical one

\begin{tabular}{lcccc}
\hline & \multicolumn{3}{c}{ Have you ever hired a freelancer in your } \\
company?
\end{tabular}

Source: Author's work 
The effectiveness of the predicted classification against the practical classification in terms of the data on hand (i.e., observed classification) was assessed to evaluate the prediction and its accuracy including the independent, predictor variables as well. With the addition of the independent variables, $74.0 \%$ of the cases could be classified correctly. In comparison with the classification table, containing only the constant of the model, where $57.8 \%$ of the cases could be classified correctly, it can be concluded that with added independent predictors, the model improved in the overall prediction of cases by $16.2 \%$.

Sensitivity was present with $80.5 \%$ accuracy, while specificity was present with $65.1 \%$ accuracy. The positive predictive value of the model is $100 *(70 \div(22+70))=$ $76.09 \%$, which means, that from all cases where it was predicted that a freelancer would be hired, $76.09 \%$ were correct, while the negative predictive value is $100 *$ $(41 \div(17+41))=70.69 \%$, representing the correctly predicted percentage of all cases where no hired freelancer was predicted.

The event of interest, which in the case of the present paper is hiring a freelancer, was determined as the positive actual state of the ROC curve, indicating that it was stated correctly. The area under the ROC curve was $0.780(95 \% \mathrm{Cl}, 0.706$ to 0.855$)$, which can be determined as good discrimination, based on the general rules of thumb of Hosmer and colleagues (Hosmer Jr. et al., 2013, p. 177).

Figure 1

Representation of the conducted ROC Curve

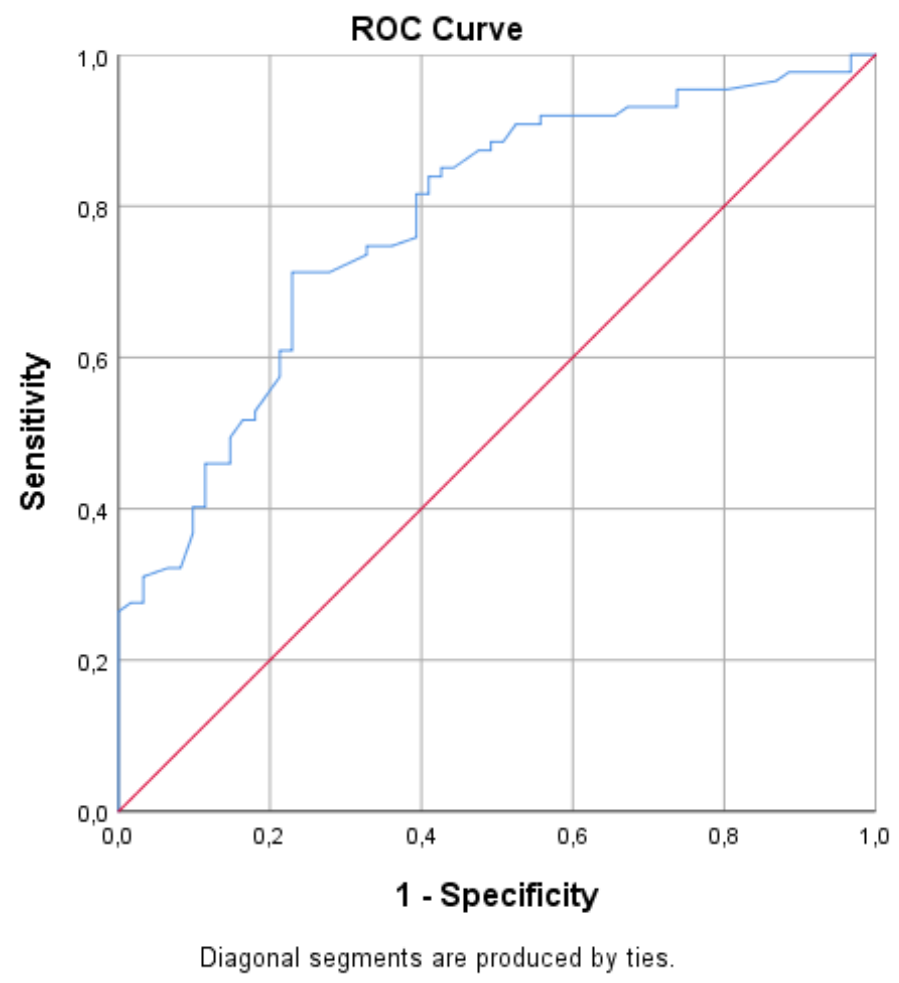

Source: Authors' work

Table 7 presents the results of the binary logistic regression model. Table 7 presents the predictors of the constructed binary logistic regression model predicting the likelihood of hiring a freelancer based on the region of the company's seat, company size, area, and type of operation 
Table 7

Binary logistic model

\begin{tabular}{lccccc|}
\hline & B & S.E. & Wald & df & p \\
\hline Region & & & 13.717 & 5 & $0.018^{* *}$ \\
\hline Central Croatia & 5.581 & 2.305 & 5.861 & 1 & $0.015^{* *}$ \\
\hline Northwestern Croatia & -1.757 & 0.863 & 4.146 & 1 & $0.042^{* *}$ \\
\hline East Croatia & 2.368 & 1.402 & 2.853 & 1 & $0.091^{*}$ \\
\hline North Adriatic and Lika & -1.713 & 1.066 & 2.582 & 1 & 0.108 \\
\hline Middle and South Adriatic & 4.566 & 2.188 & 4.356 & 1 & $0.037^{* *}$ \\
Company size & & & 11.584 & 3 & $0.009^{* * *}$ \\
\hline Little & -6.601 & 1.974 & 11.177 & 1 & $0.001^{* * *}$ \\
\hline Medium & 0.516 & 1.167 & 0.196 & 1 & 0.658 \\
\hline Large & -25.290 & 6860.678 & 0.000 & 1 & 0.997 \\
\hline Area of operation & & & 14.733 & 5 & $0.012^{* *}$ \\
\hline Regionally (more than two counties) & 7.157 & 2.843 & 6.339 & 1 & $0.012^{* *}$ \\
Croatia & 10.030 & 3.306 & 9.207 & 1 & $0.002^{* * *}$ \\
\hline Countries around Croatia & 12.196 & 3.502 & 12.128 & 1 & $0.000^{* * *}$ \\
\hline European Union & 11.158 & 3.338 & 11.177 & 1 & $0.001^{* * *}$ \\
\hline Whole world & 54.232 & 9577.221 & 0.000 & 1 & 0.995 \\
\hline Type of operation & & & 10.844 & 6 & $0.093^{*}$ \\
\hline Process industry & -6.768 & 2.701 & 6.281 & 1 & $0.012^{* *}$ \\
\hline Service activities and logistics & -11.582 & 3.865 & 8.982 & 1 & $0.003^{* * *}$ \\
\hline Services of utility and public companies & -11.170 & 3.560 & 9.847 & 1 & $0.002^{* * *}$ \\
\hline Independent professions (lawyers, dentists, etc.) & -24.090 & 26710.717 & 0.000 & 1 & 0.999 \\
\hline Agriculture and fisheries & -1.959 & 2.025 & 0.936 & 1 & 0.333 \\
\hline Education & -35.313 & 19837.403 & 0.000 & 1 & 0.999 \\
\hline Constant & 1.979 & 1.464 & 1.826 & 1 & 0.177 \\
\hline
\end{tabular}

Note: The dependent variable of the model is whether the given company have hired a freelancer (yes/no); *** statistically significant at 1\%; ** $5 \%$; ${ }^{*} 10 \%$

Source: Author's work

Based on the constructed model, three of the hereby-used independent constructs were found to be significant predictors of hiring freelancers: the region of the company's seat, company size, and area of operation.

The region of the company's seat has a significant influence on hiring a freelancer $(p=0.015)$. The City of Zagreb was set as the reference category of this variable, thus, the odds of hiring freelancers in other regions were compared to companies residing in the City of Zagreb. The results show that the odds of hiring a freelancer was significantly higher in the regions "Central Croatia" ( $B=5.581, p=0.015)$ and "Middle and South Adriatic" $(B=4.566, p=0.037)$ than in Zagreb City, however, the likelihood of hiring a freelancer was significantly lower in the region of "Northwestern Croatia" ( $B=-1.757, p=0.042)$.

The size of the company is a significant predictor of hiring a freelancer according to the results of the performed binary logistic regression model ( $p=0.009$ ). Micro companies were appointed as reference category of this predictor and the analysis revealed that little companies have significantly fewer odds of hiring freelancers than micro ones $(B=-6.601, p=0.001)$.

Table 7 interprets the odds ratios for the predictors as well (see column $\operatorname{Exp}(B)$ ), which represent the exponentiation of the analyzed coefficients. These estimates tell about the amount of increase/decrease in the odds of the dependent variable (i.e., hiring freelancers) when increasing the respective predictor with 1 unit, holding the other ones constant. 
As the model shows, the operational area of companies is also a significant predictor of hiring a freelancer ( $p=0.012)$. The reference category of this variable was local firms and as the model shows, the odds of hiring a freelancer is significantly higher in all wider operational areas: regional firms operating in more than two counties $(B=$ 7.157, $\operatorname{Exp}(B)=1283.336, p=0.012)$, Croatia-wide companies $(B=10.030, \operatorname{Exp}(B)=$ 22694.988, $p=0.002)$, firms that operate in countries around Croatia as well $(B=$ 12.196, $\operatorname{Exp}(B)=198086.893, p<0.001)$ and those that operate EU-wide $(B=11.158$, $\operatorname{Exp}(B)=70138.516, p=0.001)$. The highest odds compared to local firms for hiring freelancers were thereby shown to be companies that operate also in countries around Croatia.

The fourth construct of the model, the operation type, did not have a significant influence on hiring a freelancer $(p=0.093)$.

\section{Conclusion}

The present study aimed to discover key company-related characteristics of hiring freelancers, considering factors such as the region of the sampled companies' seats, the size of the firms, their operational areas, and operation types. This paper aimed to explore factors that might influence hiring a freelancer; research questions were proposed accordingly, each of them aiming to discover the influence of a specific factor (i.e., region, where the seat of the company is, the size of the organization, the market on which the company operates, and the type of company activity) on the employment of freelancers. To meet this goal, the binomial logistic regression analysis was conducted.

The present paper used primary data acquired from a population of small, medium, and large companies based in Croatia. An online questionnaire was used as a research instrument, and an e-mail with the link containing this survey was sent to respondents by the Croatian Chamber of Commerce. As a result, $n=158$ respondents were evaluated in the present study. Based on the considerations about the operationalization of this research, the data collection was limited to companies residing in Croatia.

Elements of the research questions proposed that the discussed independent variables are significant predictors of hiring a freelancer. $R Q 1$ proposed that the region where the company's seat is, has a significant influence on hiring a freelancer, which was accepted ( $p=0.015)$, so was RQ2 stating that the size of the company is a significant predictor in this relationship $(\rho=0.009)$ and $R Q 3$ proposing that the area of operation is a significant predictor in this model ( $p=0.012)$. RQ4, setting the type of operation as a significant predictor was, however, rejected $(p=$ 0.093). The authors should note the limitations of the study.

Research with its conclusions provides the standpoint for the freelancers for evaluation and judgment on their business possibilities. These results may give not a significant value to the companies but can open the question of considering that workforce and encourage the sustainability of their business model. In the end, there is the third cornerstone that needs to be taken into account, the national legislative part that can use the conclusions when designing developmental policies to encourage employment and especially self-employment as this is the oftendiscussed topic. Here the policy designers try to create benefits for those who selfemploy but as well, the benefits for the companies who subcontract freelancers can be taken into consideration. The scientific presentation given in this paper provides guidelines for practitioners.

The presently discussed results regarding influential factors in terms of freelancer employment need to be generalized first at the country level, in Croatia. Future 
research should therefore aim to collect data, which meets the requirements of representatively in Croatia, and verify, whether the hereby interpreted effects truly reflect freelancer employment on a national level. Further research is required in terms of country comparison as well, to provide indications for possible international generalisability, or explore the existence of possible differences in this regard.

\section{References}

1. Arsov, S., and Naumoski, A. (2014). "Transparency and Disclosure Practices in Selected Post Transition Economies". European Journal of Business and Management, Vol. 6, No. 16, pp.146-154.

Beck, U. (2000), The Brave New World of Work, Cambridge, Polity Press.

Beardwell, I., Holden, L., Claydon, T. (2004), Humane Resource Management - A Contemporary Approach, 4th Ed., Prentice Hall FT, Pearson Education, Harlow, UK. Bolarić Škare, M. (2012), "Entrepreneurship and Self-employment - Examples of Good Practice", Učenje za poduzetništvo, Vol. 2 No. 2, pp. 303-310.

Burke, A. (2015), "Introduction: A Freelancing and Self-Employment Research Agenda", in Burke A. (Ed.) The Handbook of Research on Freelancing and SelfEmployment, Senate Hall Academic Publishing, Dublin, pp. 3-8.

Cieślik, J. (2015), "Capturing Statistically the "Intermediate Zone" Between the Employee and Employer Firm Owner", in The Handbook of Research on Freelancing and Self-Employment, A. Burke, Ed., Dublin, Senate Hall Academic Publishing, pp. 2938.

Davis-Blake, A., Uzzi, B. (1993), "Determinants of Employment Externalization: A Study of Temporary Workers and Independent Contractors", Administrative Science Quarterly, Vol. 38 No. 2, pp. 195-223.

Field, A. (2018), Discovering Statistics using IBM SPSS Statistics (5th ed.), SAGE

Publications Ltd., London, UK.

Gheorghe, M. (2015), State of Freelancing in IT and Future Trends, World Academy of Science, Engineering and Technology International Journal of Social, Behavioral, Educational, Economic, Business and Industrial Engineering Vol. 9 No. 5., p. 31252.

Gönen, M. (2007), Analyzing Receiver Operating Characteristic Curves With SAS (1st ed.), Cary, NC, SAS Publishing.

Harland, C., Knight, L., Lamming, R., Walker, H. (2005), "Outsourcing: assessing the risks and benefits for organisations, sectors and nations", International Journal of Operations \& Production Management, Vol. 25 No. 9, pp. 831-850.

Henning, G. K. (2011), "Corporation and Polis", Journal of Business Ethics, Vol. 103 No. 2, pp. 289-303.

Hoedemaekers, C. (2020), "Selling themselves: conceptualising key features of freelance work experience", Culture and Organization, https://doi.org/10.1080/14759551.2020.1833206.

Hosmer Jr., D. W., Lemeshow, S., \& Sturdivant, R. X. (2013), Applied Logistic Regression (3rd ed.), Hoboken, NJ, USA: John Wiley \& Sons.

Johnson, S.A., Ashforth, B.E. (2008), "Externalization of Employment in a Service Environment: The Role of Organizational and Customer Identification", Journal of Organizational Behavior, Vol. 29 No. 3, pp. 287-309.

Kazia, A. G., Yusoffb, R. M., Khana, A., Kazib, S. (2014), "The Freelancer: A Conceptual Review", Sains Humanika, Vol. 2 No. 3, pp. 1-7. 
Kavčić, K., Bončina, K., Suklan, J., Milost, F. (2015a), "Development design of outsourcing strategies: The case of Slovenia", Ekonomski pregled, Vol. 66 No. 5, pp. 455-476.

Kavčić, K., Gošnik, D., Beker, I., Suklan, J. (2015b), "How does Logistics Outsourcing Influence Organisation Performance?", International Journal of Industrial Engineering and Management (IJIEM), Vol. 6 No. 3, pp. 101-107.

Kitching, J., Smallbone, D. (2012), "Are Freelancers A Neglected Form Of Small Business?", Journal Of Small Business and Enterprise Developmnet, Vol.19 No. 1, pp. 74-91.

Kitching, J. (2015), "Tracking UK Freelance Workforce Trends 1992-2015", in Burke A. (Ed.) The Handbook of Research on Freelancing and Self-Employment, Dublin, Senate Hall Academic Publishing, pp. 15-28.

Kozica A., Bonss, U., Kaiser, S. (2014), "Freelancers and the absorption of external knowledge: practical implications and theoretical contributions", Knowledge Management Research and Practice, Vol. 12 No. 4, pp. 421-431.

Leighton, P., Brown, D. (2013), "Future working: The rise of Europe's independent professionals (iPros), European Forum of Independent Professionals. Available at https://apo.org.au/node/201721 / (15 Mar 2021)

Malaga, R. A. (2016), "Digital Micro Entrepreneurship a Preliminary Analysis - Case studies from the gig economy", Journal of Business and Economics, Vol. 7, No. 9, pp. 1469-1476.

Marshall, D., Ambrose, E., Mclvor, R., Lamming, R. (2015), "Self-interest or the greater good: How political and rational dynamics influence the outsourcing process", International Journal of Operations and Production Management, Vol. 35 No. 4, pp. 547-576.

Mason, C., Carter, S., Tagg, S. (2010), "Insignificant Businesses: the characteristics of home-based businesses in the United Kingdom, Regional Studies, Vol. 45 No. 5, pp. 625-639,

Nagelkerke, N. J. D. (1991), "A Note on a General Definition of the Coefficient of Determination", Biometrika, Vol. 78 No. 3, pp. 691-692.

Piltan, M., Sowlati, T. (2016) , "Multi-criteria assessment of partnership components", Expert Systems with Applications, Vol. 64, pp. 605-617.

Ruiz, Y., Walling, A. (2005), "Home-based working using communication technologies Recent trends in teleworking, using data from the Labour Force Survey", Labour market trends October, pp. 417-426.

Shepard, J. M. (2018), "Understanding Co-Working with The Growth and Development of Freelancers", Management and Organizational Studies, Vol. 5, No. 2, pp. 1-6.

Steyerberg, E. W. (2009), "Clinical Prediction Models". International Statistical Review. New York, NY: Springer New York.

Volberda, H.W. (1998), Building the Flexible Firm: How to Remain Competitive, Oxford University Press, New York. 


\section{About the authors}

Ana Globočnik Žunac is an Assistant professor at University North with Ph. D in information-communication sciences. She was executive director of HEl, and later assistant of vice-rector for scientific work and international affairs at University North. She was a visiting lecturer at University in Prague and University in Tirana. She took part in many conferences and has numerous publications. She was twice awarded for the best paper and was praised for the exceptional contribution to the development of the Department of Communication and PR. The author can be contacted at agzunac@unin.hr

Sanja Zlatic graduated from the Faculty of Natural Sciences and Mathematics in Zagreb in the field of financial and business mathematics. She is a lecturer of mathematics and operational research at University North in Croatia. She is a Ph.D. student at the International Joint Cross-Border Ph.D. Programme in International Economic Relations organized and administered by the Consortium of Universities in Bratislava, Sopron, Pula, Varaždin, Mostar, and Prague and collaboration with the University of Applied Sciences Burgenland (UAS), Eisenstadt, Austria. She was awarded the best speaker at the SGEM Conference on Social Sciences and Arts 2018 - Albena, Bulgaria. The author can be contacted at sazlatic@unin.hr

Krešimir Buntak is a professor at University North. After finishing the University of Engineering and Shipbuilding in Zagreb, he gained his Ph.D. in economics. During his education, he worked over 20 years in management positions from the public and local governments, through the private sector to large export organizations in the automotive industry. Since 2004, he has taught at various national and international schools and colleges about managing, management, organization, business economics, BPM, quality management systems, and business excellence. He is the author of more than 100 scientific and technical papers and one polytechnic textbook. The author can be contacted at kresimir.buntak@unin.hr 